\title{
Brief Electrical Stimulation Triggers an Effective Regeneration of Leech CNS
}

\author{
Sharon Cohen, ${ }^{1,2,3}$ Alon Richter-Levin, ${ }^{1,2,3}$ and Orit Shefi ${ }^{1,2,3}$
}

https://doi.org/10.1523/ENEURO.0030-19.2020

${ }^{1}$ Faculty of Engineering, Bar-llan University, Ramat Gan 5290002, Israel, ${ }^{2}$ Bar-Ilan Institute of Nanotechnology and Advanced Materials, Bar-Ilan University, Ramat Gan 5290002, Israel, and ${ }^{3}$ Gonda Multidisciplinary Brain Research Center, Bar-Ilan University, Ramat Gan 5290002, Israel

\section{Visual Abstract}

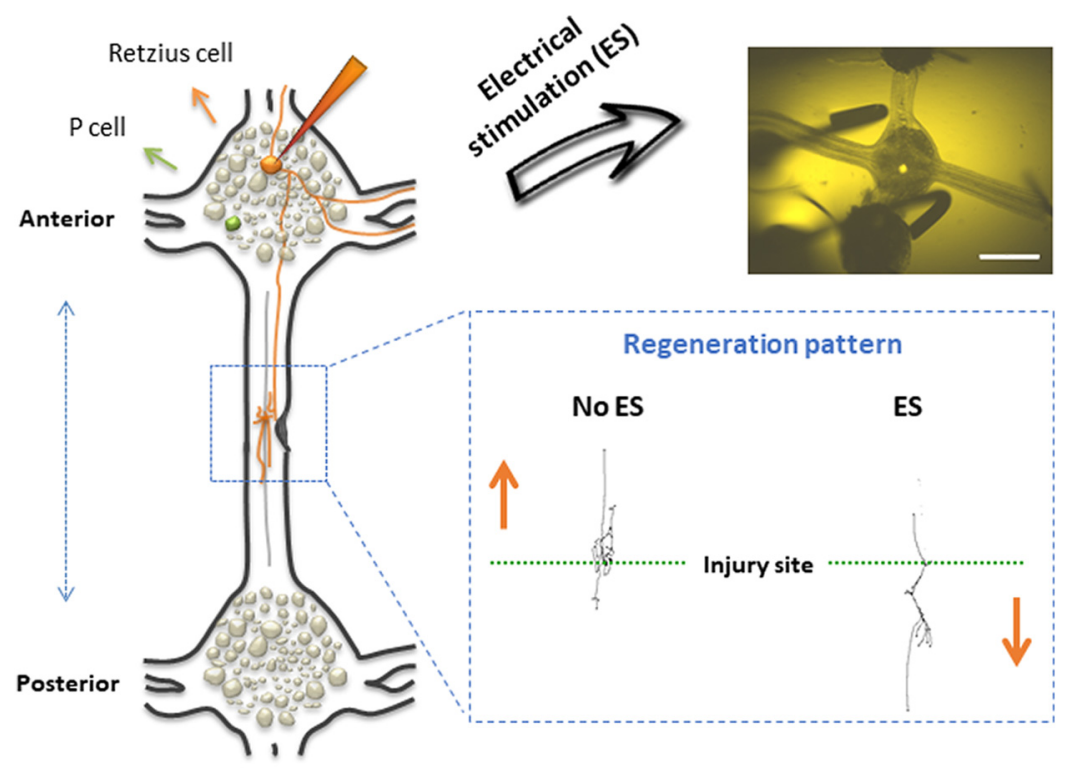

The search for therapeutic strategies to promote neuronal regeneration following injuries toward functional recovery is of great importance. Brief low-frequency electrical stimulation (ES) has been reported as a useful method to improve neuronal regeneration in different animal models; however, the effect of ES on single neuron behavior has not been shown. Here, we study the effect of brief ES on neuronal regeneration of the CNS of adult medicinal leeches. Studying the regeneration of selected sets of identified neurons allow us to quantify

\section{Significance Statement}

Recent studies have demonstrated that brief electrical stimulation (ES) can improve neuronal regeneration. However, the effect of ES on single neuron behavior has not been shown. In the current study, we use a relatively simple nervous system, the adult medicinal leech, label identify neurons, and study the effects of ES on their regeneration. We show that different neurons response differently to the same ES paradigm. Following brief ES $(20 \mathrm{~Hz}, 30 \mathrm{~min})$, more neuronal branches of the Retzius cells traverse the injury site with better directed growth. In addition, more microglial cells were detected in proximity to the stimulation site compared with the non-stimulated nervous systems. We conclude that ES triggers efficient neuronal regeneration and this effect might be mediated through differential microglial distribution. 
the ES effect per cell type at the single-cell level. Chains of the CNS that were subjected to cut injury were observed for $3 \mathrm{~d}$, and the spontaneous regeneration was compared with the electrically stimulated injured chains. We show that the ES improves the efficiency of regeneration of Retzius cells, as larger masses of the total branching tree traverse the injury site with better directed growth with no effect on the average branching tree length. No antero-posterior polarity was found along regeneration within the leech CNS. Moreover, the microglial cell distribution was examined revealing more microglial cells in proximity to the stimulation site compared with non-stimulated. Our results lay a foundation for future ES-based neuroregenerative therapies.

Key words: CNS; electrical stimulation; glial cells; medicinal leech; regeneration; single cell

\section{Introduction}

The central nervous system (CNS) neurons of adult mammals fail to regenerate their lost axons following an injury. In contrast, the peripheral nervous system (PNS) and nervous systems of lower organisms have an intrinsic ability to undergo substantial regeneration (Ferretti et al., 2003; Becker and Becker, 2008; Huebner and Strittmatter, 2009; Mladinic et al., 2009; Ferreira et al., 2012). The unique ability of neuronal tissue to regenerate in some but not other species and what leads nerve regeneration toward functional recovery are longstanding questions that have not yet been solved. Neuronal regeneration has been intensively studied and many efforts have been put into developing methods to increase its effectiveness (Rodríguez et al., 2000; Siemionow and Brzezicki, 2009; Giger et al., 2010; Ferguson and Son, 2011; Baldwin and Giger, 2015). Some of the findings have demonstrated that directing the axonal outgrowth toward appropriate targets by means of physical support, can significantly improve the outcome (Kim et al., 2008; Ferrari et al., 2011; Baranes et al., 2012a,b, 2016; Alon et al., 2014, 2015; Antman-Passig and Shefi, 2016; Marcus et al., 2017). It was also shown that directionality can be achieved by chemical guidance (Dodd and Jessell, 1988; Miller et al., 2002; Rosoff et al., 2004; Kennedy et al., 2006; von Philipsborn et al., 2006; Li et al., 2008; Giger et al., 2010; Lee et al., 2014; CarballoMolina et al., 2016).

Natural bioelectricity has an important role in many fundamental cellular processes in all cell types (Hoff, 1936; Geddes and Hoff, 1971; Piccolino, 1997; McCaig et al., 2005, 2009; Fixler et al., 2012; Tasset et al., 2012; Podda et al., 2014; Adler et al., 2016; McLean and Verge, 2016). In neurons, ion transporters generate voltage gradients and fluxes that lead to fast dynamic voltage changes, e.g., action potentials, or steady and long-lasting voltage.

Received January 23, 2019; accepted May 6, 2020; First published May 29, 2020.

The authors declare no competing financial interests.

Author contributions: S.C. and O.S. designed research; S.C. and A.R.-L. performed research; S.C. analyzed data; S.C. and O.S. wrote the paper.

This work was partially supported by the Israel Science Foundation Individual Grant \#1053/15.

Acknowledgements: We thank Moshe Karni for his valuable help with the electrical stimulation setup and Gil Rudnitsky for his important advice with the fluorescence microscopy.

Correspondence should be addressed to Orit Shefi at orit.shefi@biu.ac.il.

https://doi.org/10.1523/ENEURO.0030-19.2020

Copyright (C) 2020 Cohen et al.

This is an open-access article distributed under the terms of the Creative Commons Attribution 4.0 International license, which permits unrestricted use, distribution and reproduction in any medium provided that the original work is properly attributed.
Upon injury, these natural electrical signals change (Song et al., 2004). Stimulating the electrical activity of the nervous tissue was found to affect neuronal growth (Patel and Poo, 1982; Ming et al., 2001; Wood and Willits, 2006; Ou et al., 2012) and has been suggested as a stimulating mechanism for neuronal repair (Hoffman, 1952; Borgens et al., 1981, 1990, 1999; Nix and Hopf, 1983; Pockett and Gavin, 1985; Borgens, 1999; Song et al., 2004; English et al., 2007; Messerli and Graham, 2011). Recent studies have demonstrated a regenerative effect even when applying brief external electrical stimulation (ES). For example, Al-Majed and colleagues have applied low frequency ES $(20 \mathrm{~Hz})$ for time periods ranging from $1 \mathrm{~h}$ to two weeks and showed that the ES dramatically accelerated the axonal regrowth of motor neurons and that they were better directed into the appropriate pathways. They have shown that short- and long-term stimulation were equally effective (Al-Majed et al., 2000a). Subsequently, their group and others have demonstrated an improved regeneration for sensory neurons as well (Brushart et al., 2005; Geremia et al., 2007; Singh et al., 2012; Wong et al., 2015). Recently, Elzinga and colleagues have examined the effects of the ES paradigm for delayed nerve repair showing an effective repair as in the case of immediate treatment (Elzinga et al., 2015). On the other hand, other studies conducted in the CNS have shown that ES promotes sprouting but not regeneration. Previous work have shown that following pyramidotomy to the corticospinal tract (CST), a daily application of ES to the motor cortex (M1), for a period of $10 \mathrm{~d}$, caused robust sprouting of CST axons in the impaired side (Brus-Ramer et al., 2007; Carmel et al., 2010; Zareen et al., 2017). The duration of daily stimulation was depended on the type of stimulation and could range from $6 \mathrm{~h}$ of multipulse stimulation (MPS) to $30 \mathrm{~min}$ of intermittent theta burst stimulation (iTBS). The observed difference between sprouting and regeneration following ES cannot be automatically attributed to the difference between the CNS and the PNS, nor to the difference between the types of the stimulation.

Although experimental results of the regeneration of populations of axons are promising, the data regarding the precise effect of ES are still controversial and to date the effect of ES on single neuron behavior has not been shown. Moreover, due to neuronal heterogeneity, different cell types with different functions and targets may respond differently to the same ES protocol (Hathway et al., 2009). Previous studies have showen that, intrinsically, different types of neurons demonstrate different regeneration capabilities (Duan et al., 2015; Hu et al., 2016; Jacobs et al., 1997; Wu et al., 2007). Hence, observations of selected identified 
A

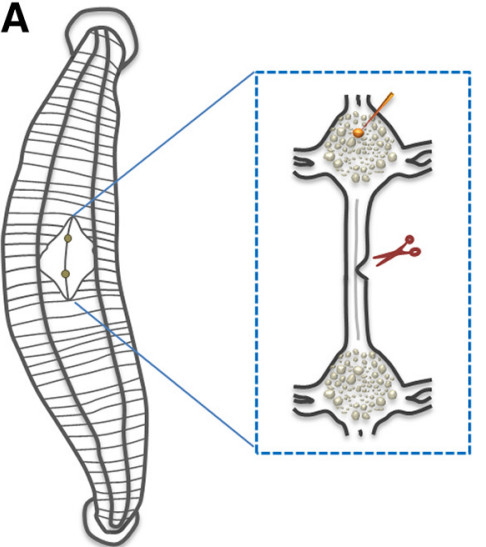

B

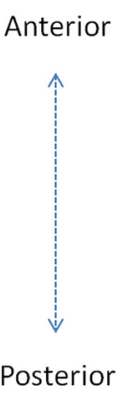

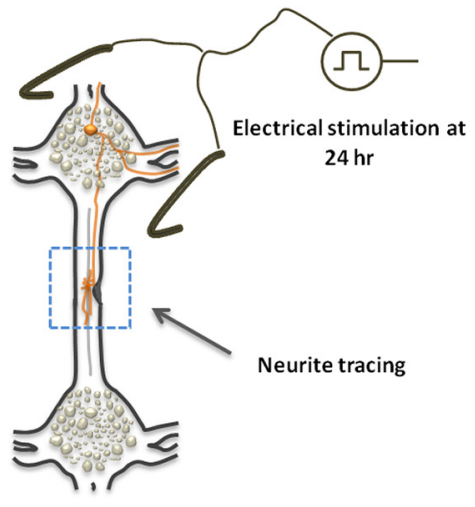

Figure 1. Schematic overview of the experimental procedure. $\boldsymbol{A}$, Leech dissection was performed for the isolation of ganglia chain (enlarged insert). An identified neuron was fluorescently labeled by microinjection (orange) and a partial cut was made to one of the two connectives. B, Ganglia chains were left to recover either spontaneously, or following a brief ES applied $24 \mathrm{~h}$ after injury. Newly formed axonal branches were traced at the injury site $72 \mathrm{~h}$ after injury (blue dashed square).

neurons may significantly reduce biological noise resulting from population averaging, and may allow for detailed characterization of the axon response to the ES.

Simple model systems such as that of invertebrates that allow the analysis of identified cells within the intact arrangement may be beneficial. Despite the differences in complexity between the vertebrate and the invertebrate nervous systems, the latter has been proven to be useful for understanding basic mechanisms related to neurophysiology, development, and regenerative biology (Baylor and Nicholls, 1971; Brenner, 1974; Ready and Nicholls, 1979; Bellen et al., 2010; Kandel, 2012). The CNS of the adult leech has been a useful model for studying these topics over 50 years (Kuffler and Nicholls, 1966; Macagno, 1980; Kristan et al., 2005; Firme et al., 2012; Tomina and Wagenaar, 2017; Puhl et al., 2018). It is finite and relatively simply interconnected. It is comprised of a head ganglion, 21 mid-body ganglia, and a tail ganglion that are joined by two lateral connectives and one smaller medial connective called Faivre's nerve (Coggeshall and Fawcett, 1964). Each mid-ganglion, except $\# 5$ and \#6, contains $\sim 400$ highly accessible neurons (Macagno, 1980). The neurons of the adult leech CNS can be unambiguously identified based on a typical size, spatial location and electrical properties (Cohen et al., 2019). Importantly, the leech CNS undergoes spontaneous and relatively fast repair following injury (Macagno et al., 1985; Chiquet and Nicholls, 1987; von Bernhardi and Muller, 1995; Wang et al., 2005; Mladinic et al., 2009). Furthermore, the involvement of microglial cells in the regeneration process following neuronal injury was first shown in this model (Sieger and Peri, 2013), and it was used to elucidate the signaling pathways that mediate their migration and crosstalk with the damaged neurons (Morgese et al., 1983; McGladeMcCulloh et al., 1989; Chen et al., 2000; Duan et al., 2003, 2009; Ngu et al., 2007; Schikorski et al., 2008; Salzet and Macagno, 2009; Croq et al., 2010; Samuels et al., 2010; Tahtouh et al., 2012; Arafah et al., 2013; Le Marrec-Croq et al., 2013; Drago et al., 2014).

In this study, we examined the promoting impact of brief ES on the regeneration of the leech CNS. We specifically focused on one type of identified neurons, the Retzius cells. These are neuromodulatory neurons, the largest within each ganglion, sending their axonal projections to adjacent ganglia through the connectives. They are involved in various leech behaviors including swimming, crawling and local bending (Tomina and Wagenaar, 2017). As a comparison, we examined the $P$ cells that are mechanosensory neurons, responding to moderate pressure to the leech ventral $(\mathrm{Pv})$ or dorsal $(\mathrm{Pd})$ skin by specific spiking patterns that encode different spatial and temporal features of the stimuli (Nicholls and Baylor, 1968; Pirschel and Kretzberg, 2016). We examined the morphology and activity of both types (Retzius and Pd cells), within the intact adult leech CNS, following an injury inflicted by a partial cut of the ganglia chain ex vivo. The identified neurons were labeled and their regeneration was assessed over $72 \mathrm{~h}$, with and without ES. In addition, we analyzed the ES-induced response of microglial cells within the injured connectives.

\section{Materials and Methods}

\section{Animals and dissection}

Ganglia chains were isolated from the CNS of adult medicinal leeches Hirudo medicinalis (Fig. 1A). All leeches are hermaphrodites. Leeches were anesthetized on ice for 30 min before dissection and were pinned, dorsal side up, to a layer of Sylgard on the bottom of the dissection chamber. Dissection was made according to an established procedure (Titlow et al., 2013). Briefly, a longitudinal cut was made through skin and muscle layers along the dorsal midline of the leech to expose the nerve cord and segmental ganglia. Short segments of CNS chains comprised of two adjacent ganglia joined by connective tissue, were then dissected and moved to a Sylgard-148 Petri dish containing $4 \mathrm{ml}$ of room temperature enriched Leibovitz medium (L15 medium supplemented with $6 \mathrm{mg} /$ $\mathrm{ml}$ glucose, $0.1 \mathrm{mg} / \mathrm{ml}$ gentamycin, $2 \mathrm{~mm} / \mathrm{ml}$ glutamine, and $2 \%$ fetal bovine serum). Next, ganglia chains were pinned on the Sylgard layer, ventral aspect up. After 


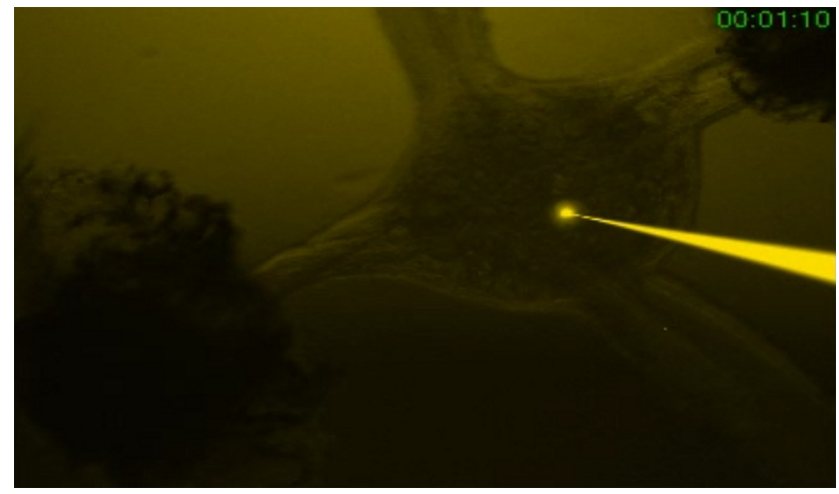

Movie 1. Retzius labeling by intracellular injection. Injection electrode was filled with 5\% Fluoro-Ruby and positioned toward the Retzius neuron. The neuron identified according to its typical location and size. Following cell penetration, we applied positive current of $15 \mathrm{nA}$ to move the dye out of the electrode into the cell. [View online]

pinning the chains, we specifically labeled the anterior right side Retzius cells in accordance with a description below. For the P cell experiments, we labeled the Pd cell on the injured side. The chain orientation was kept the same for all chains. Partial axotomy was then performed by cutting one of the two connective tissues (i.e., the connective that includes the axonal projection of the labeled cell) with fine scissors. Finally, the L15-enriched medium was replaced with fresh medium, and the injured ganglia chains were left to recover in the $25^{\circ} \mathrm{C}$ incubator up to the ES part.

\section{Neuronal labeling by intracellular injection}

Sharp injection micropipettes were pulled from borosilicate glass capillaries of 1-mm external diameter and 0.75-mm internal diameter using a p-1000 micropipette puller (Sutter instruments). A resistance of 15-25 M $\Omega$ was obtained by filling the micropipettes with $3 \mathrm{~m}$ potassium acetate. To visualize a single regenerating axon within the CNS, we examined different fluorescent dyes based on previous reports of the leech nervous system and other invertebrate neurons that have shown effective tracing of fine neuronal structure (Fan et al., 2005; Shefi et al., 2006). Dextran amine conjugated dyes (Alexa Fluor and FluroRuby) were found to be ideal for our purpose. Hence, for labeling, micropipettes were filled with either 3-5\% Alexa Fluor 488/568 (catalog \#D-22910/D-22912) or 3-5\% Fluoro-Ruby (catalog \#AG335). Since the Retzius cells are the largest pair of cells situated on the mid-ventral surface of each segmental ganglion and are characterized by a typical spontaneous electrical activity, they were highly accessible and very easily identifiable. P cells, on the other hand, may be confused with other cells in their environment, and their electrical activity must be monitored for unambiguous identification. By using a micromanipulator, we positioned the filled micropipette in the desired cell, impaled it, and injected the dye iontophoretically with a positive current of 15-35 nA for $30 \mathrm{~s}$ to $1 \mathrm{~min}$ (Movie 1). This short-time injection was found to be sufficient to label the desired cell for further analysis. Using the same micropipette, we monitored the neuronal activity of the cell before and after dye injection to verify cell viability along the procedure. Signals were amplified (molecular devices multi clamp 700B), filtered and digitized by an analog-to-digital board Digidata 1400A (Axon Instruments).

\section{ES}

Twenty-four hours after injury (day 1), a single ES was applied to the experimental chains (Fig. 1B). The control chains received sham ES. In order to precisely control the electrode progression toward the stimulation location, we designed and constructed a generic light aluminum electrode holder that allowed the coupling of the platinum iridium parallel bipolar hook electrodes (FHC - PBAA08100) with a three-axis motorized micromanipulator. We used the micromanipulator to place the electrodes next to the ganglia chain near the ganglion. Specifically, cathode and anode were placed at opposed sides of the ganglion. The electrodes were connected to a function generator and an ES of continuous $20-\mathrm{Hz}$ square wave, positive polarity, and amplitude of $500 \mathrm{mV} / \mathrm{mm}, 1 \mathrm{~V} / \mathrm{mm}$, or $3 \mathrm{~V} / \mathrm{mm}$ was generated for $30 \mathrm{~min}$. Subsequently, the electrodes were removed and the medium was replaced with a fresh sterile medium. The ganglia chains were allowed to recover in a $25^{\circ} \mathrm{C}$ incubator for additional $48 \mathrm{~h}$.

\section{Morphometric analysis}

Newly formed axons were detected at the injury site 72 $\mathrm{h}$ after connective partial cut. For each ganglia chain, Z-stack images from the injury site were acquired with a fluorescence microscope (Leica Z16-APO) equipped with the LAS Montage Module for acquiring a series of Z-Stack images and with the appropriate filters of FITC and TRIRC. We measured the morphometric parameters of the newly formed branches with or without ES. These included total branching tree length and the percentage of nerve processes succeeding in crossing the injury site for each regenerating neuron. To measure neural length in the 3D tissue, we used the simple neurite tracer plugin of the Fiji ImageJ software (National Institutes of Health; Meijering et al., 2004), which enables semiautomatic neurite tracing and length measurements for the fluorescently labeled regenerating axons. To measure the percentage of nerve processes which crossed the injury site, we set the point at which the axon had been cut as a reference point and calculated the proportion of the total branches length that crossed this point out of the total branching tree length of the entire regenerated axon.

\section{Microglia distribution analysis}

Ganglia chains were isolated, pinned on the Sylgard layer, and were subjected to a partial cut injury as described earlier (see also Fig. 1A). Injured ganglia chains, experimental and control, were placed in the $25^{\circ} \mathrm{C}$ incubator to allow microglial cell migration toward the injury site, as described previously. Twenty-four hours after injury, an ES at $20 \mathrm{~Hz}$ for 30 min was provided only for the 
A

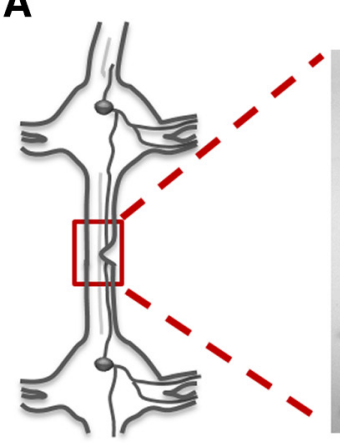

$\mathbf{O h r}$

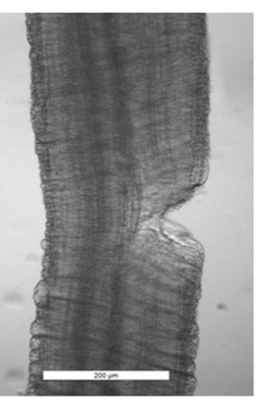

$24 \mathrm{hr}$

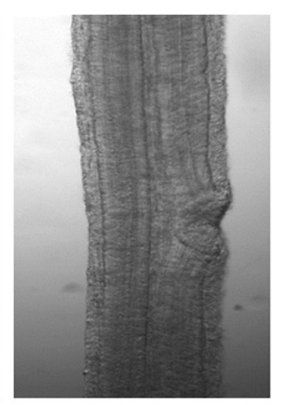

$48 \mathrm{hr}$

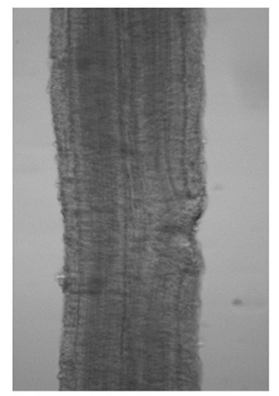

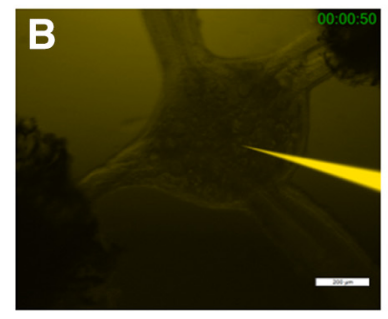
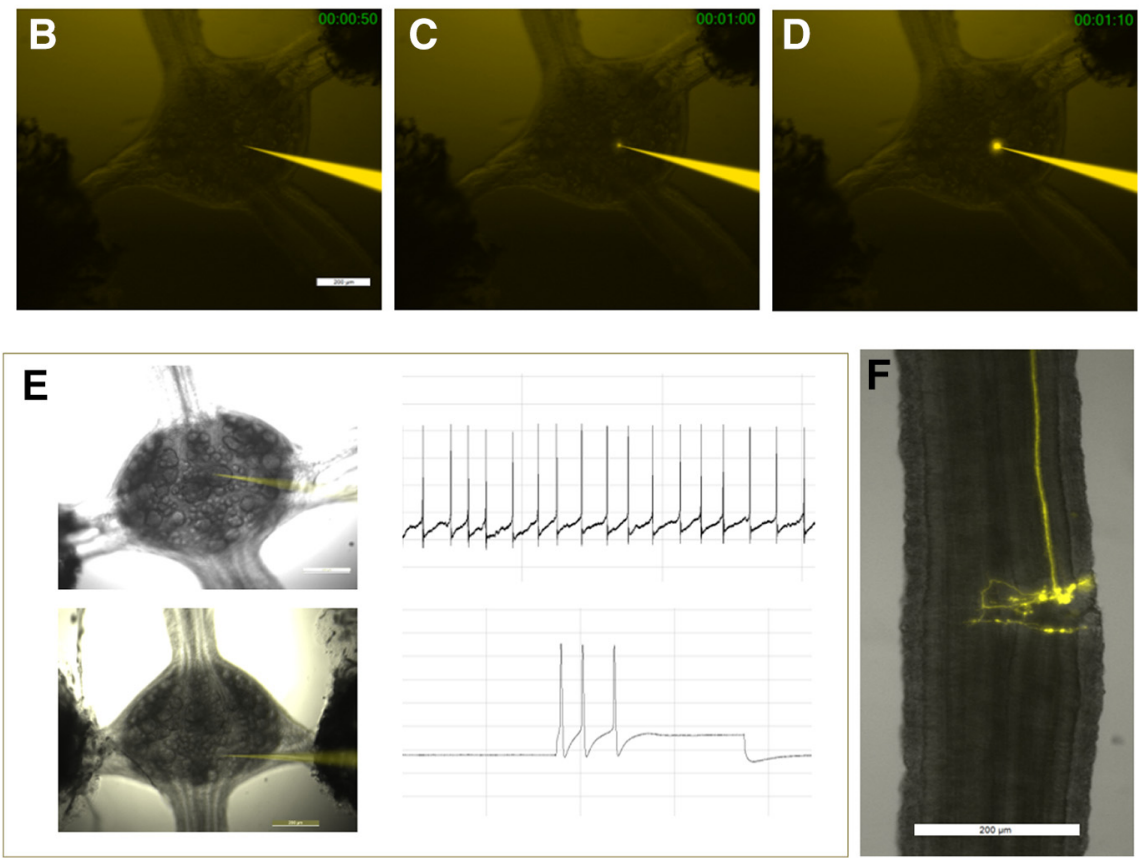

Figure 2. Tracing newly regenerated axonal branches of an identified neuron within the recovering leech CNS. $\boldsymbol{A}$, Spontaneous regeneration process of the connective tissue following partial axotomy of one of the connectives. $\boldsymbol{B}-\boldsymbol{D}$, Microinjection of a single neuron with Fluoro-Ruby for a period of up to $1 \mathrm{~min}$. Time lapse images demonstrate the procedure. $\boldsymbol{E}$, Retzius cell (upper panel) and $\mathrm{P}$ cell (lower panel) identified according to their typical location, size, and characteristic electrical activity pattern. The dye-filled recording electrode can be seen in bright orange in both images. $\boldsymbol{F}$, Fluorescent dye demonstrates the elaborated trajectory of the newly regenerated axonal branches of the Retzius neuron following an injury. Scale bar $=200 \mu \mathrm{m}(\boldsymbol{A}-\boldsymbol{F})$.

experimental ES group, whereas the control group underwent sham stimulation. L15 medium was then replaced, and chains were returned to the incubator for additional $24 \mathrm{~h}$. Next, $48 \mathrm{~h}$ after injury, cell nuclei were stained with SybrGreen fluorescent dye, to observe cell distribution along the chains. To note, some of the nuclei, a minority of the entire population, were those of the perineurial sheath cells and another one nucleus belonging to the single glial cell related to the connective. Since perineurial sheath cells do not move following injury, a change in the number of cells is mainly caused by a change in the microglial cell population (as noted by McGlade-McCulloh et al., 1989). A series of fluorescent Z-stack images were acquired from two regions of the connective: by the ES site and by the injury site. Cells were counted manually by using Fiji ImageJ software, and the total number of cells for each condition was obtained and compared.

\section{Experimental design and statistical analyses}

Measurements of the investigated parameters are summarized in bar plots. Values were expressed as a mean \pm $\mathrm{SE}$. The unpaired two-tailed and one-tailed (when direction of outcome is predictable) Student's $t$ test were used to determine statistical significance; $p<0.05$ was considered statistically significant. The number of samples and the statistical analysis for each panel, including specific $p$ values, are indicated when appropriate in each figure legend in the results section.

\section{Results}

\section{Regeneration of single cells within ex vivo ganglia chain following a cut model}

Illustration of the model system and the experimental procedure can be seen in Figure 1. The two steps of the 

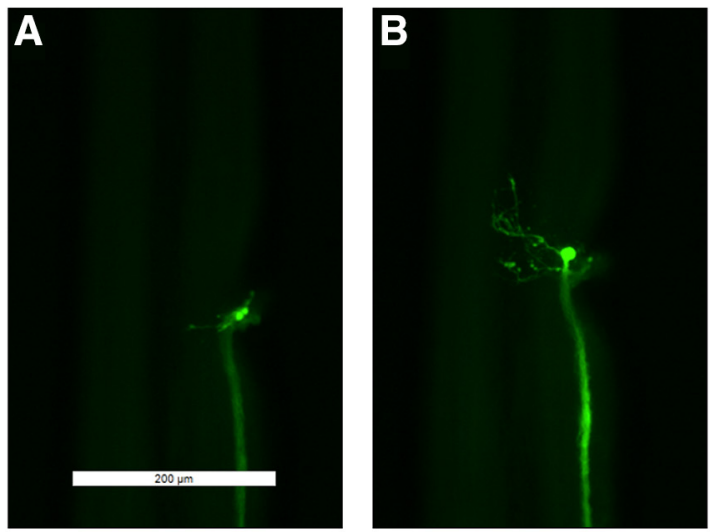

D

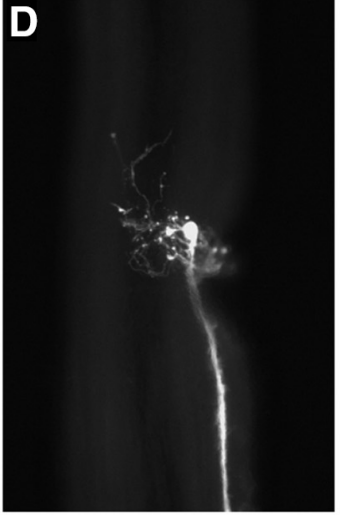

E

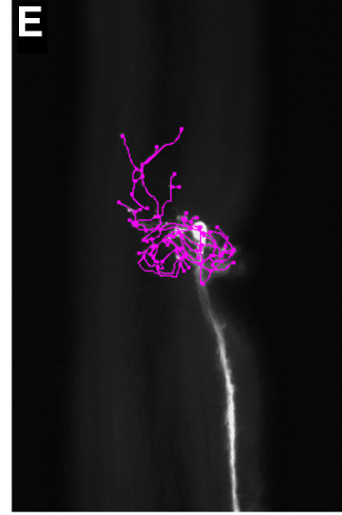

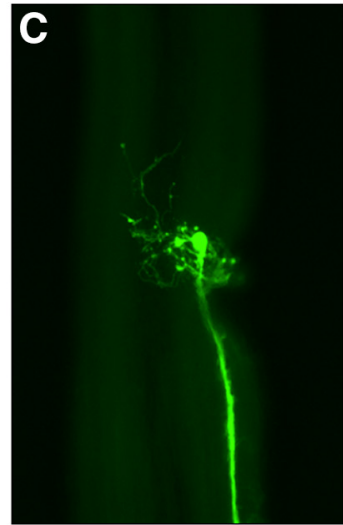

$\mathbf{F}$

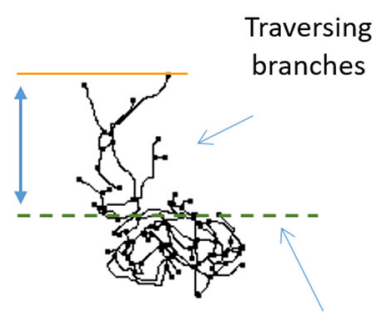

Injury site
G

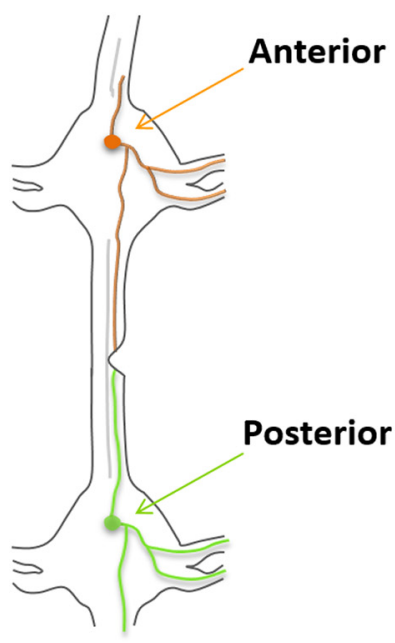

H

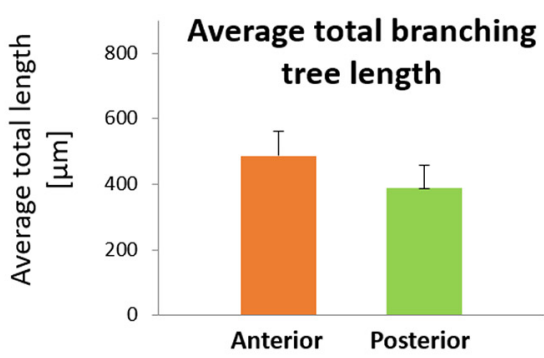

$\left.{ }^{100}\right] \quad$ Injury site traversing

Figure 3. Antero-posterior polarity during CNS spontaneous regeneration. $\boldsymbol{A}-\boldsymbol{C}$, Fluorescence images of a single labeled Retzius neuron's newly formed branches at time points 24,48 , and $72 \mathrm{~h}$ after injury, respectively. $\boldsymbol{D}$, $\boldsymbol{E}$, Morphologic measurements method. Neurite tracing of the newly formed branches (pink) was performed by the semi-automated simple neurite tracer plugin. $\boldsymbol{F}$, FIJ drawing representing an example of typical newly formed axonal branches. The drawing shows the relative portion of mass that crosses the injury site out of the total newly branching tree. G, Illustration of antero-posterior polarity examination. Retzius cells were microinjected either at the anterior $(n=16)$ or the posterior $(n=19)$ ganglion. Cells that exhibited successful regeneration after $72 \mathrm{~h}$ (i.e., cells with $>150 \mu \mathrm{m}$ newly regenerated axonal branches) were further analyzed. $\boldsymbol{H}$, Averaged total lengths of the newly formed axonal branches (no significant difference). $I$, Percentage of axonal branches crossing successfully the injury site (no significant difference). $N=15$ per group, two-tailed unpaired $t$ test. Scale bar $=200 \mu \mathrm{m}$. 
A

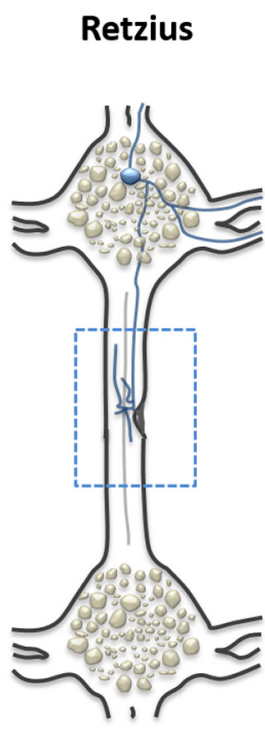

$P$ cell

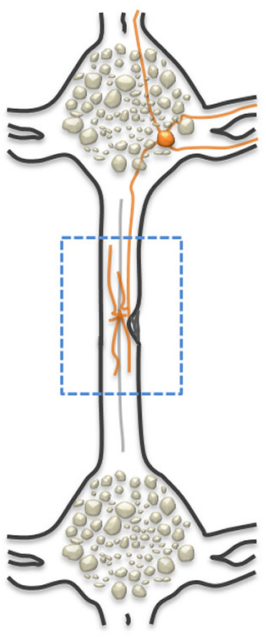

B Average total branching tree length
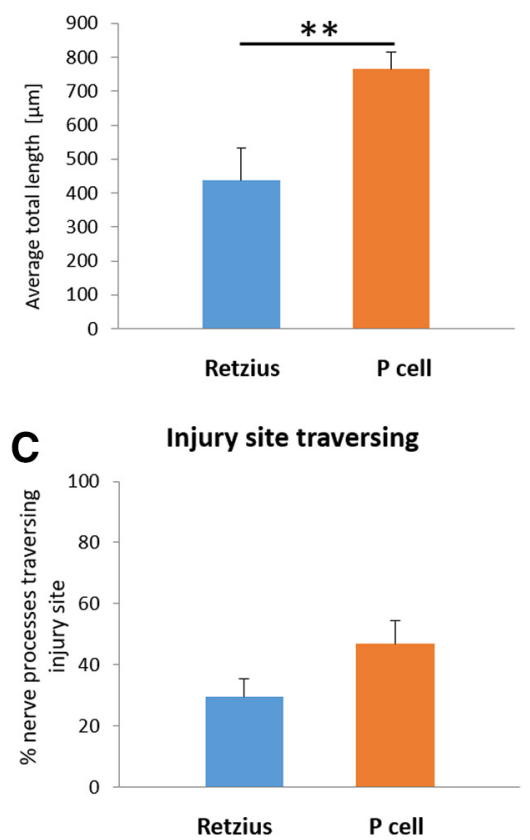

Figure 4. Different types of neurons demonstrate different spontaneous regeneration. $\boldsymbol{A}$, Illustration of the single Retzius and $\mathrm{P}$ cell tracing. $\boldsymbol{B}$, Total branching length of spontaneously regenerated Retzius and $\mathrm{P}$ cells. Two-tailed unpaired $t$ test; $* p=0.0019$. $\boldsymbol{C}$, Injury site traversing of spontaneously regenerated Retzius and P cells.

preparation include the ganglia chain isolation and injury (Fig. 1A), and the regeneration following brief ES (Fig. 1B).

The spontaneous regeneration of the injured ganglia chain can be seen in Figure $2 A$. A recovery of the connective tissue could be detected already $24 \mathrm{~h}$ after injury. Figure $2 B$ shows a recording electrode (bright orange) impaling the soma of a large Retzius cell before labeling. After impaling the cell, dye was injected iontophoretically (Fig. 2B-D). To verify neuronal viability following the injury and the labeling procedure, we monitored the spontaneous spike activity of the injected Retzius neurons or evoked potentials in the injected $\mathrm{P}$ cells before and after dye injection (Fig. 2E). All neurons retained their typical spike activity following the procedure. Figure $2 F$ demonstrates the newly regenerated axonal branches of the Retzius neuron $72 \mathrm{~h}$ after injury, revealing an elaborated growth at the injury site with a complex branching tree pattern.

\section{Comparison between anterior and posterior cell spontaneous regeneration shows no CNS polarity}

To characterize the spontaneous regeneration process of neurons that have not received ES, we stained the neurons, traced the regenerating trajectories and followed the recovery up to $72 \mathrm{~h}$ after the cut. Figure 3 shows a typical regeneration process in a single neuron as imaged 24,48 , and $72 \mathrm{~h}$ after injury. A dynamic axonal regeneration can be seen, indicating that the neuron remained viable. To evaluate functional regeneration, we calculated the proportion length of the branches that crossed the injury site (traversing branches) out of the total branching tree of the regenerated axon (Fig. 3F). Next, we examined whether there is a distinguishable antero-posterior polarity within the leech CNS that may affect the spontaneous injury site traversing. We obtained axonal tracing of regenerating Retzius neurons from both anterior and posterior ganglia (relative to cut location; Fig. 3G). No significant difference between the two groups was found in the average branching tree length $(487 \pm 75$ vs $389 \pm 70 \mu \mathrm{m}$, respectively; Fig. $3 H$ ) nor in the percentage of axonal branches mass succeeding in crossing the injury site $(20 \pm 7$ vs $37 \pm 10$, respectively; Fig. 3/). The results indicate that there is no CNS polarity that may affect the spontaneous injury site crossing with respect to Retzius spontaneous regeneration.

\section{Typical spontaneous regeneration patterns for identified sets of neurons}

To evaluate whether different types of neurons may exhibit different regeneration features following injury, we compared Retzius to $\mathrm{P}$ cells spontaneous regeneration. $\mathrm{P}$ cells from both anterior and posterior ganglia $(n=18)$ were compared with the Retzius neurons, also taken from anterior and posterior ganglia $(n=29)$. The different types of cells demonstrated different basal behavior. The results indicate that $\mathrm{P}$ cells were able to significantly regenerate larger branching tree compared with the regenerating Retzius neurons $(764 \pm 96$ vs $436 \pm 51 \mu \mathrm{m}$, respectively; Fig. 4B). In addition, $\mathrm{P}$ cells demonstrated a relatively higher rate of injury site crossing compared with the Retzius neurons ( $47 \pm 8$ vs $29 \pm 6$, respectively; Fig. 4 C). However, this effect was not statistically significant. 
A

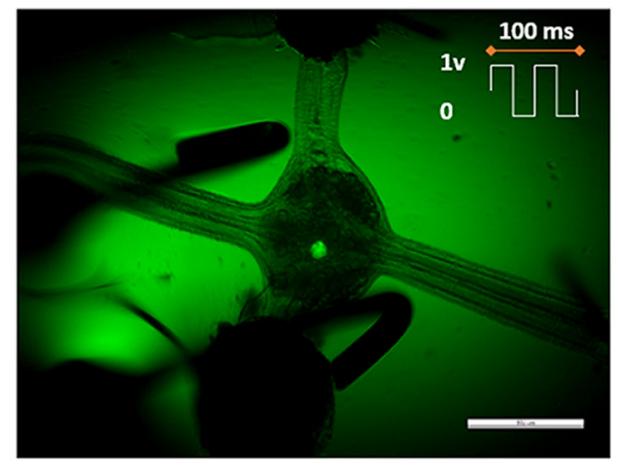

C

\section{No ES}

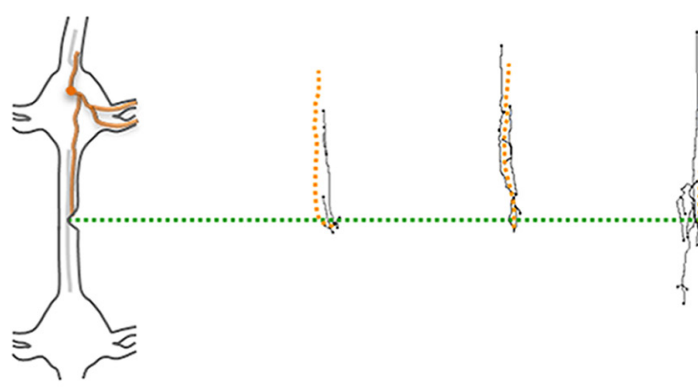

B
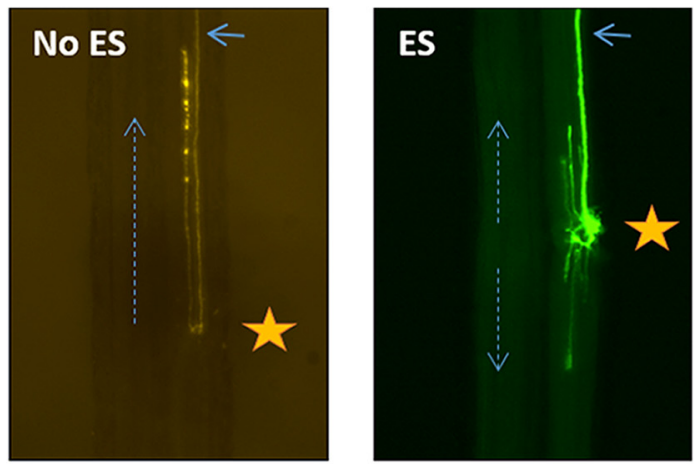

\section{Proximal}

Injury site

Distal

Proximal

Injury site

ES

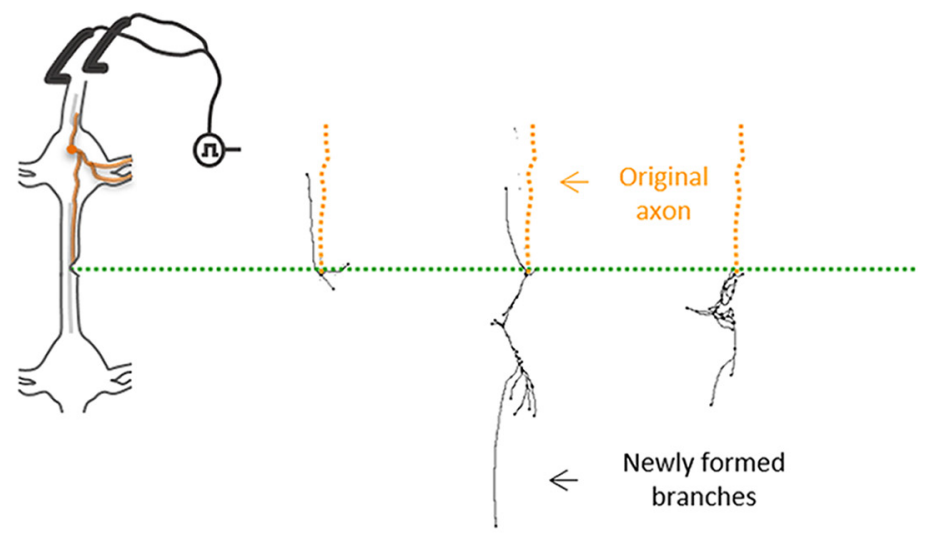

\section{Distal}

Original axon

Injury

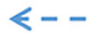

new branches
D

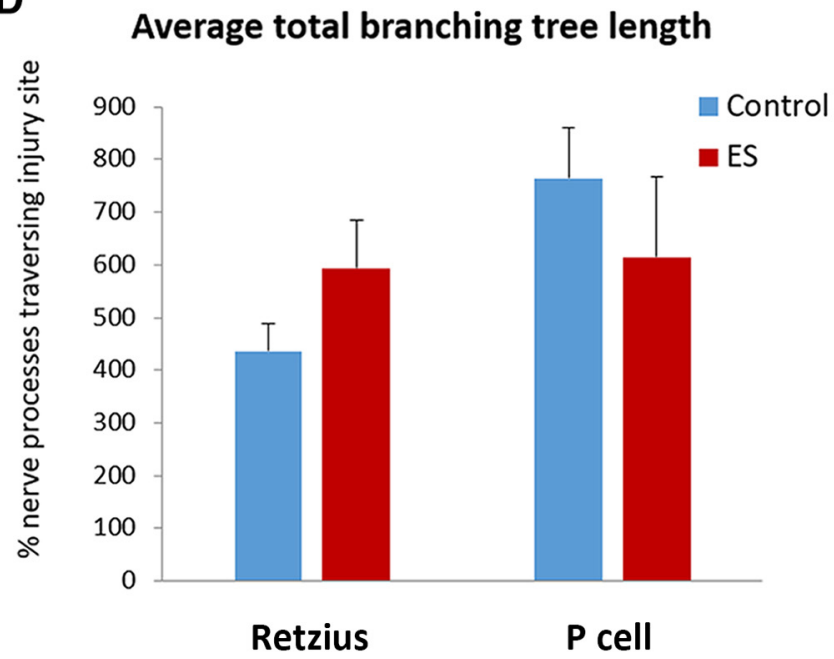

E

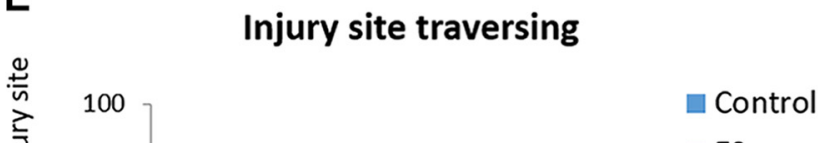

Figure 5. Morphologic analyses for Retzius and $\mathrm{P}$ cells regeneration with and without $\mathrm{ES}$. $\boldsymbol{A}$, Fluorescence image of the ganglion stimulation. The bipolar hook electrode was positioned in the desired location so that the ganglion was situated in the center. The pattern of the ES is displayed at upper right corner. B. Fluorescence images of the Retzius cell's newly formed branches at $72 \mathrm{~h}$, 
continued

with and without ES (green and orange, respectively). C, Representative examples of three ganglia chains from a single leech for each condition. Upper panel, Chains with no ES treatment. Lower panel, Chains treated with ES. The axonal tracing drawings of the newly formed branches were placed on an artificial line that illustrates the relative position of the injury site (green dotted line). The original axon is marked by the orange dotted line and the newly formed branches are in black. The portion of the axonal tree located under the green dotted line is the mass that crossed the injury site. $\boldsymbol{D}$, Total branching length of Retzius and $P$ neurons in non-stimulated (left bar) and stimulated (right bar) chains. $\boldsymbol{E}$, Percentage of injury site crossing of Retzius and $P$ neurons in non-stimulated (left bar) and stimulated (right bar) chains. One-tailed unpaired $t$ test; $* p=0.041 ; n=40$ (Retzius cells) and 26 ( $\mathrm{P}$ cells).

These data clearly show that different types of cells may present different responses and that by exploring single neurons this information becomes visible.

\section{Injury site traversing by regenerative axons significantly increased following brief ES for Retzius neurons}

To examine the effects of ES on the regeneration we applied a brief ES $(20 \mathrm{~Hz}, 1 \mathrm{~V} / \mathrm{mm})$ to the ganglia chain $24 \mathrm{~h}$ after injury (Fig. $5 \mathrm{~A}$ ) and quantitatively analyzed the morphology of the labeled neurons after another $48 \mathrm{~h}$. This intensity was chosen according to an earlier study that demonstrated positive effect of ES on neurite outgrowth of goldfish retinal explants (Ou et al., 2012). Based on previous studies showing improved regeneration following $\mathrm{ES}$ in comparison to spontaneous regeneration (Borgens et al., 1981; Nix and Hopf, 1983; Borgens, 1999; Al-Majed et al., 2000a; Brushart et al., 2005; Gordon et al., 2009; Carmel et al., 2010; Ou et al., 2012; Singh et al., 2012; Elzinga et al., 2015; Wong et al., 2015; Gordon, 2016; Zareen et al., 2017; MacEwan et al., 2019), we compared the ES-treated versus non-treated cells (using one-tailed $t$ test) in analyzing the ES effect. Examples of typical regeneration patterns of Retzius cells with and without ES are shown in Figure $5 B$. Axonal tracing drawings of newly formed branches demonstrate that larger mass of branches crossed the injury site and were directed toward their original target, the distal ganglion, following an ES as compared with spontaneous regeneration of the unstimulated group (Fig. 5C).

Comparison between the average branching tree length of regenerating Retzius neurons with and without application of ES showed that there is no significant difference between the groups ( $593 \pm 90$ vs $436 \pm 51 \mu \mathrm{m}$, respectively; Fig. 5D). However, a comparison between branches' directionality of regenerating Retzius neurons with and without application of ES showed a significant increase in percentage of axonal branches (length) which successfully crossed the injury site. For stimulated Retzius cells, the regenerating branches mass that crossed the injury site increased significantly to an average percentage of $51 \pm 11 \%$, whereas the unstimulated Retzius cells showed an average percentage of only $29 \pm 6 \%$ (Fig. $5 E$ ). This result reflects an almost twofold increase, similar to the increase reported for populations of rat sensory and motoneurons (Elzinga et al., 2015). To examine the effect of the ES amplitude on the ability of axons to cross the injury site, we repeated the procedure with higher $(3 \mathrm{~V} / \mathrm{mm})$ and lower $(500 \mathrm{mV} / \mathrm{mm})$ amplitudes. Application of ES with lower amplitude of $500 \mathrm{mV} / \mathrm{mm}(n=6)$ led to similar statistics as for the amplitude of $1 \mathrm{~V} / \mathrm{mm}$ $(61 \pm 10 \%$ vs $51 \pm 11 \%$, respectively). However, the application of higher ES amplitude of $3 \mathrm{~V} / \mathrm{mm}$ resulted in an immediate observable damage to the ganglion, reflected in a distortion of its shape. In an attempt to clarify the nature of the axons outgrowth with and without ES, we analyzed the number of branches for each condition. The average number of branches was similar for cells with and without the electrically stimulation ( $7.6 \pm 1.0$ vs $6.3 \pm 0.7$ branches, respectively). This result suggests that the ES affect the outgrowth directionality without changing the level of axon sprouting.

The analysis of $\mathrm{P}$ cells morphology led to different growth behavior than the Retzius cells. Application of ES had no effect of the rate of injury site crossing that was close to $50 \%$ even without the ES stimulation ( $48 \pm 11$ vs $47 \pm 8$, for stimulated and non-stimulated, respectively; Fig. 5E). In addition, there was no significant difference in $P$ cells branching tree length with or without the brief ES (614 \pm 154 vs $764 \pm 96$, respectively; Fig. $5 D$ ).

\section{Injured ganglia chains present different microglial cell distribution following brief ES}

To examine whether brief ES alters the microglial cell response during leech CNS recovery, we labeled the cell nuclei along the connective $48 \mathrm{~h}$ after injury and compared the number of cells with that found in the untreated chains. As it has been shown that the nuclei in the connective are mostly those of microglial cells, and that there are no other migrating cells along the connectives other than microglia (McGlade-McCulloh et al., 1989; Samuels et al., 2010), a change in the number of nuclei along the connective can be attributed mainly to a change in the microglial cells population. For each condition we analyzed two regions in the connective: near the ES site, i.e., the anterior region, and close to the injury site (Fig. $6 A$ ). Figure $6 B$ demonstrates a preferential accumulation of glial cells at the injury site, as differential fluorescence intensity with higher values can be seen in the injured chains in comparison to a lower and relatively homogeneous fluorescence intensity observed in the non-injured chains. As for the anterior region of the chain, close to the ES site, a higher number of cells was detected in the electrically stimulated injured chains compared with the non-treated ones. As shown in Figure $6 C, D$, there was a significant difference in the total number of cells counted at the anterior region between the two groups ( $380 \pm 40$ vs $250 \pm 20$, respectively).

\section{Discussion}

Simple model systems of invertebrates are beneficial for studying the basic principles of nervous system regeneration (Baylor and Nicholls, 1971; Ready and Nicholls, 1979; Yanik et al., 2004; Yan et al., 2009). One such 
A

Electrical stimulation

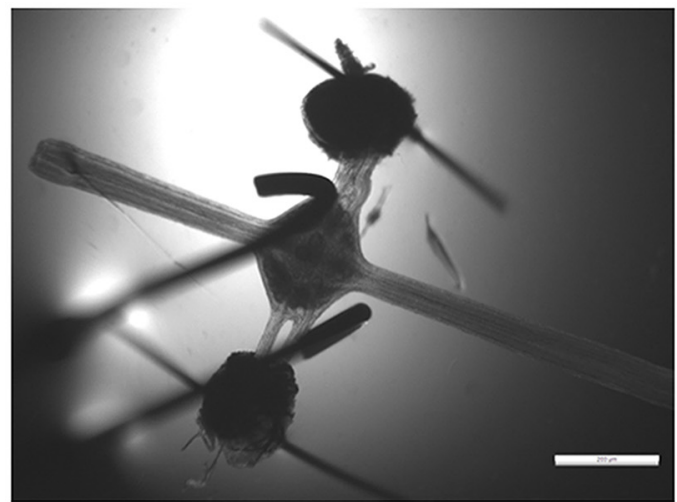

B
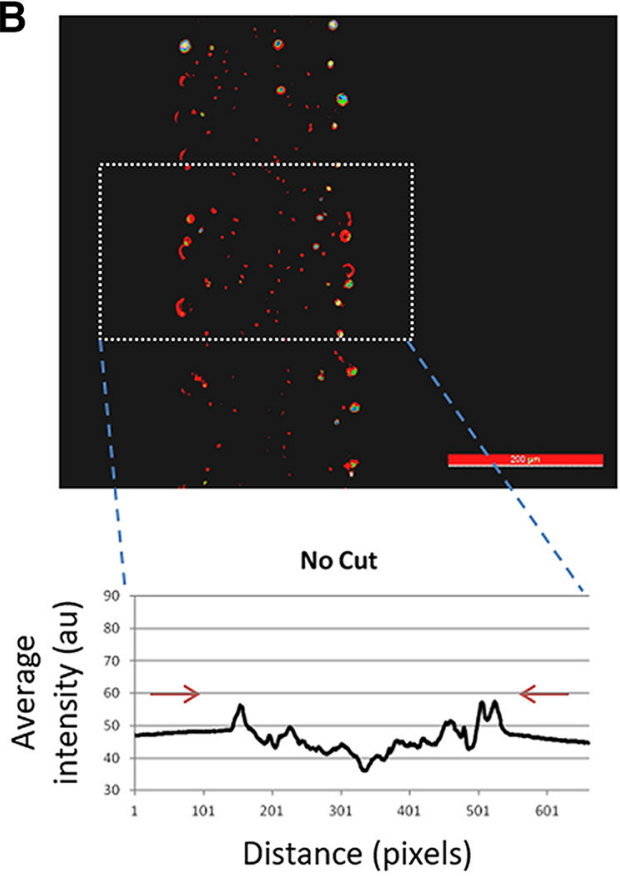

C NoES
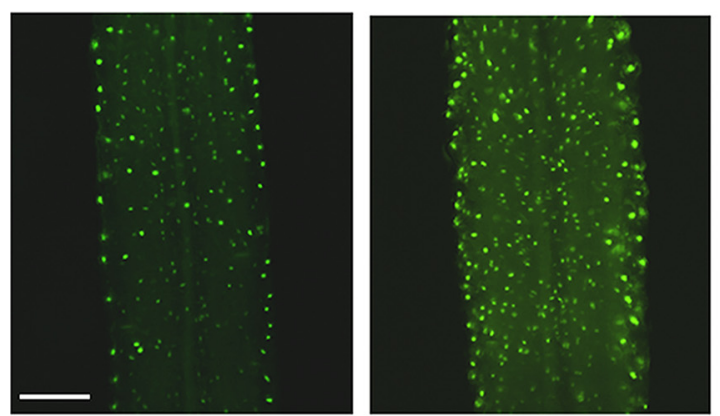

$\Omega$
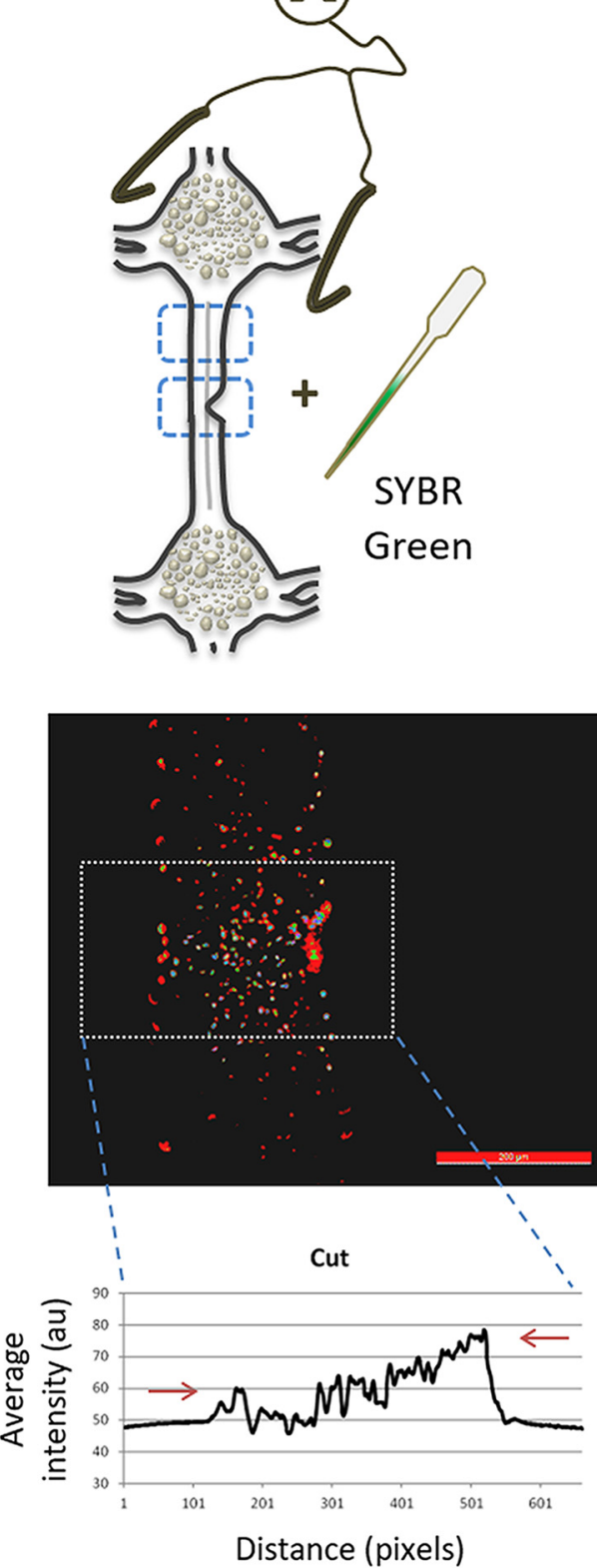

D

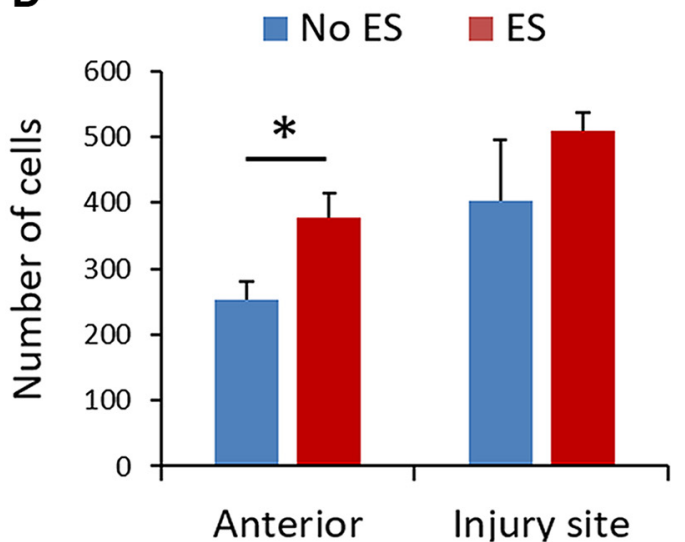

Figure 6. Electrical effect on leech microglia. $\boldsymbol{A}$, Illustration of the experimental procedure demonstrating cell nuclei staining with 
continued

SYBR Green in the vicinity of the location of ES and at the region of interest for analysis (blue dotted rectangles). $\boldsymbol{B}$, Measurement of SYBR Green intensity profiles in cells within the leech connective. The fluorescence intensity ( $y$-axes) measured from left to right along the rectangular regions ( $x$-axes) were plotted. Cell distribution intensity profile shows accumulation of cells at the injury site and increased values for the side that matches the injury area as compared with relatively uniform values in the uninjured chain. The images show the cells after pseudo-color processing. Blue and green represents high intensity, red represents low intensity. C, Visualization of SYBR Green-labeled microglia distribution and accumulation following partial cut with and without ES. Fluorescence images show increased number of cells at the anterior region only for the ES group. $\boldsymbol{D}$, Average number of cells at the two regions of interest with and without ES. Asterisk indicates that the cell number near the ES site (anterior) was significantly increased under brief ES; $* p=0.048, n=3-4$ CNS ganglia chains per group, two-tailed unpaired $t$ test. Scale bar $=200 \mu \mathrm{m}(\boldsymbol{A}-\boldsymbol{C})$.

preparation is the CNS of the medicinal leech, H. medicinalis, in which spontaneous regeneration that leads to functional recovery can occur. Using a cut injury model of the nervous system of the medicinal leech, we were able to analyze the regeneration process of identified neurons at the single cell level with and without ES. For each ganglia chain, we anterogradely labeled single cell body. We analyzed specific cells, the Retzius neurons, which are paired serotonergic neurons with the largest somas in the ganglion, and traced the branching morphology at the injury site for up to $3 \mathrm{~d}$. Our results show that Retzius neurons exhibit successful spontaneous regeneration within this period; however, the vast majority of the regenerating branches fail to regrow across the lesion site and most of them turn backwards. To examine the advantage of labeling specific type of neurons, we tested the spontaneous regeneration behavior of a second type of neurons, the $P$ cells. We found a distinct growth pattern for each cell type with higher level of efficient injury site crossing for the $P$ cells. Previous studies already demonstrated different regeneration capabilities to different neuronal subtypes. Duan et al. (2015), for example, showed that following an injury to the mouse optic nerve, and subsequent treatment that elicits regeneration, only one specific subtype of the retinal ganglion cells (RGCs) out of 11 subtypes, the $\alpha$ RGCs, was accounted for nearly all the observed regeneration. In the Caenorhabditis elegans several mechanosensory neurons such as the PLM, ALM, and AVM show robust regeneration (Wu et al., 2007), while other sensory neurons, such as the AFD and AWC, show no regeneration following axotomy (Chung et al., 2006; Gabel et al., 2008). In the sea lamprey, following an hemisection of its spinal cord, some neurons, such as the Mauthner, I1, B1, and B3 neurons, display poor regenerative capacity, while others, such as the M4, 13-16, B2, and B6, show high regenerative capacity (Jacobs et al., 1997). The differences in the regeneration capabilities are attributed to intrinsic differences between neuron types (Jacobs et al., 1997; Shifman and Selzer, 2007; Chen et al., 2016; Chen and Shifman, 2019), which may also mediate different regenerative responses to the same ES.

Previously, using different models has shown that axonal regeneration and preferential re-innervation following brief ES is accelerated (Al-Majed et al., 2000a; Gordon et al., 2009; Singh et al., 2012; Elzinga et al., 2015).

Analyzing neurons that can be unambiguously identified allowed us to quantify the effect of the ES per cell type. Following ES, in contrast to the backward regrowth typically exhibited along the Retzius spontaneous regeneration, the regenerated axonal branches of the Retzius cells changed their directionality without changing the total branching tree length. We found that brief ES affected the typical tree directionality and promoted its ability to cross the injury site. Branches that succeeded in crossing the injury site were able to keep growing toward the adjacent target ganglion. This approach revealed a way to overcome the limited regeneration following a cut-induced injury, which acts as a more rigid barrier for axons to cross as compared with other injuries such as crushes (Macagno et al., 1985). Indeed, Macagno et al. (1985) have demonstrated an extremely poor ability of $T$ cells (mechanosensory neurons) to cross the injury site following a cut compared with crushing the connective. In addition, they found that the T cells in a cut model typically reverse the regrowth direction toward the original ganglion, as we have noticed in our experiments for the $\mathrm{Rz}$ neurons. However, this phenomenon is not the same for all neurons. We examined another set of mechanosensory neurons ( $P$ cells) and found that half of the axonal tree could cross spontaneously the injury site. These results show a typical regrowth pattern and are in accordance with pervious results of another model system, the sea lamprey, that showed the tendency of some axons to regenerate across the lesion, rather than loop backward (Mackler et al., 1986; Lurie and Selzer, 1991). The limited improvement of injury site crossing of $P$ cells with ES application may represent a ceiling effect, raising an interesting question for future study. Thus, the effect of ES, as we showed here, may contribute to an efficient and functional regeneration pattern for cells that otherwise tend to turn backward at the injury site, improving the natural effectiveness of regeneration.

To rule out an immanent anterio-posterior polarity within the adult ganglia chain, which may lead to the backward regeneration trend, we examined the spontaneous regeneration pattern for both anterior and posterior Retzius neurons (relative to the injury site). No significant difference was detected regardless of whether the neuron was regenerating from the anterior ganglion to the posterior or vice versa. This shows that the tendency to loop back is not affected by the position of injured neuron and this behavior is a result of the regeneration after injury. This result strengthens our conclusion that the spontaneous recovery, after a partial cut injury, has a backward-regeneration trend and that the brief ES interferes with this pattern to some extent, leading to a more efficient pattern of regrowth.

Previous studies suggested that action potentials generated by the ES are transmitted back to the soma of the neurons, potentially promotes upregulation of BDNF and 
other neurotrophic factors and their receptors and are essential for enhancing axonal growth following stimulation (Al-Majed et al., 2000a,b, 2004; English et al., 2007; Geremia et al., 2007; Elzinga et al., 2015; Gordon, 2016). The blockade of the retrograde transmission of these action potentials by TTX prevented the positive effect of the ES on the axonal outgrowth. So far, none of the canonical neurotrophic factors (NGF, BDNF, CD3/4, and GDNF ligands) have been found in the invertebrate nervous system (Palgi et al., 2009). Therefore, we seek for other evolutionary conserved mechanisms that can be involved in mediating the ES effect. Different models, including mammalian nervous systems, revealed that glial cells are activated following nerve injury (Schwartz, 2003; Davalos et al., 2005; David and Kroner, 2011). In addition, in diverse models including mice and rats, it has been shown that microglial cells respond rapidly to any minor neuropathological change (Kreutzberg, 1996; Hanisch and Kettenmann, 2007). In the leech, microglial cells recruitment at the injury site is known to be involved in the regeneration process. Previous studies have suggested that, within the leech CNS, cells start moving toward the injury site within minutes after injury, reaching peak level within $24 \mathrm{~h}$ and then decline slowly for weeks after injury (Morgese et al., 1983; McGlade-McCulloh et al., 1989; Le Marrec-Croq et al., 2013). We, therefore, also analyzed the migration and distribution of microglial cells in injured ganglia chains, electrically stimulated and non-stimulated. Following the injury, we observed greater accumulation of microglial cell close to the stimulating area (between the anterior ganglion and the injury site) in ganglia chains that received ES. At the injury site, a considerable accumulation of cells was observed for both cases, but no significant ES-induced difference was detected between those groups. Our findings that brief ES increased the axonal crossing of the injury site and affected microglial cells' migration lead to the conclusion that the modifications in axonal growth direction following a brief ES might be mediated by ES through differential microglial cells distribution. Activating microglial subpopulations by different factors has been reported previously in the leech (Croq et al., 2010; Tahtouh et al., 2012) and also in mammals (Hanisch and Kettenmann, 2007), leading to neuroprotective or neurotoxic effects. Our findings of amended growth pattern and, most importantly, efficient neuronal regeneration triggered electrically are intriguing with high potential for promoting neuronal repair. Moreover, the observed brief ES-induced supported functional regrowth, which was able to overcome the physical obstacle formed by a scar, opens new possibilities for future therapeutics.

\section{References}

Adler D, Fixler D, Scheinowitz M, Shainberg A, Katz A (2016) Weak electromagnetic fields alter $\mathrm{Ca}$ + handling and protect against hypoxia-mediated damage in primary newborn rat myotube cultures. Pflugers Arch 468:1459-1465.

Al-Majed AA, Neumann CM, Brushart TM, Gordon T (2000a) Brief electrical stimulation promotes the speed and accuracy of motor axonal regeneration. J Neurosci 20:2602-2608.

Al-Majed AA, Brushart TM, Gordon T (2000b) Electrical stimulation accelerates and increases expression of BDNF and trkB mRNA in regenerating rat femoral motoneurons. Eur J Neurosci 12:4381-4390.
Al-Majed AA, Siu LT, Gordon T (2004) Electrical stimulation accelerates and enhances expression of regeneration-associated genes in regenerating rat femoral motoneurons. Cell Mol Neurobiol 24:379-402.

Alon N, Miroshnikov Y, Perkas N, Nissan I, Gedanken A, Shefi O (2014) Substrates coated with silver nanoparticles as a neuronal regenerative material. Int J Nanomed 9:23-31.

Alon N, Havdala T, Skaat H, Baranes K, Marcus M, Levy I, Margel S, Sharoni A, Shefi O (2015) Magnetic micro-device for manipulating PC12 cell migration and organization. Lab Chip 15:2030-2036.

Antman-Passig M, Shefi O (2016) Remote magnetic orientation of 3D collagen hydrogels for directed neuronal regeneration. Nano Lett 16:2567-2573.

Arafah K, Croix D, Vizioli J, Desmons A, Fournier I, Salzet M (2013) Involvement of nitric oxide through endocannabinoids release in microglia activation during the course of CNS regeneration in the medicinal leech. Glia 61:636-649.

Baldwin KT, Giger RJ (2015) Insights into the physiological role of CNS regeneration inhibitors. Front Mol Neurosci 8:23.

Baranes K, Chejanovsky N, Alon N, Sharoni A, Shefi O (2012a) Topographic cues of nano-scale height direct neuronal growth pattern. Biotechnol Bioeng 109:1791-1797.

Baranes K, Kollmar D, Chejanovsky N, Sharoni A, Shefi O (2012b) Interactions of neurons with topographic nano cues affect branching morphology mimicking neuron-neuron interactions. J Mol Histol 43:437-447.

Baranes K, Shevach M, Shefi O, Dvir T (2016) Gold nanoparticle-decorated scaffolds promote neuronal differentiation and maturation. Nano Lett 16:2916-2920.

Baylor DA, Nicholls JG (1971) Patterns of regeneration between individual nerve cells in the central nervous system of the leech. Nature 232:268-270.

Becker CG, Becker T (2008) Adult zebrafish as a model for successful central nervous system regeneration. Restor Neurol Neurosci 26:71-80.

Bellen HJ, Tong C, Tsuda H (2010) 100 years of Drosophila research and its impact on vertebrate neuroscience: a history lesson for the future. Nat Rev Neurosci 11:514-522.

Borgens RB (1999) Electrically mediated regeneration and guidance of adult mammalian spinal axons into polymeric channels. Neuroscience 91:251-264.

Borgens RB, Roederer E, Cohen MJ (1981) Enhanced spinal cord regeneration in lamprey by applied electric fields. Science 213:611617.

Borgens RB, Blight AR, McGinnis ME (1990) Functional recovery after spinal cord hemisection in guinea pigs: the effects of applied electric fields. J Comp Neurol 296:634-653.

Borgens RB, Toombs JP, Breur G, Widmer WR, Waters D, Harbath AM, March P, Adams LG (1999) An imposed oscillating electrical field improves the recovery of function in neurologically complete paraplegic dogs. J Neurotrauma 16:639-657.

Brenner S (1974) The genetics of Caenorhabditis elegans. Genetics 77:71-94.

Brus-Ramer M, Carmel JB, Chakrabarty S, Martin JH (2007) Electrical stimulation of spared corticospinal axons augments connections with ipsilateral spinal motor circuits after injury. J Neurosci 27:13793-13801.

Brushart TM, Jari R, Verge V, Rohde C, Gordon T (2005) Electrical stimulation restores the specificity of sensory axon regeneration. Exp Neurol 194:221-229.

Carballo-Molina OA, Sánchez-Navarro A, López-Ornelas A, LaraRodarte R, Salazar P, Campos-Romo A, Ramos-Mejía V, Velasco I (2016) Semaphorin 3C released from a biocompatible hydrogel guides and promotes axonal growth of rodent and human dopaminergic neurons. Tissue Eng Part A 22:850-861.

Carmel JB, Berrol LJ, Brus-Ramer M, Martin JH (2010) Chronic electrical stimulation of the intact corticospinal system after unilateral injury restores skilled locomotor control and promotes spinal axon outgrowth. J Neurosci 30:10918-10926. 
Chen J, Shifman MI (2019) Inhibition of neogenin promotes neuronal survival and improved behavior recovery after spinal cord injury. Neuroscience 408:430-447.

Chen A, Kumar SM, Sahley CL, Muller KJ (2000) Nitric oxide influences injury-induced microglial migration and accumulation in the leech CNS. J Neurosci 20:1036-1043.

Chen J, Laramore C, Shifman MI (2016) Differential expression of HDACs and KATs in high and low regeneration capacity neurons during spinal cord regeneration. Exp Neurol 280:50-59.

Chiquet M, Nicholls JG (1987) Neurite outgrowth and synapse formation by identified leech neurones in culture. J Exp Biol 132:191206.

Chung SH, Clark DA, Gabel CV, Mazur E, Samuel ADT (2006) The role of the AFD neuron in $C$. elegans thermotaxis analyzed using femtosecond laser ablation. BMC Neurosci 7:30.

Coggeshall RE, Fawcett DW (1964) The fine structure of the central nervous system of the leech, Hirudo medicinalis. J Neurophysiol 27:229-289.

Cohen S, Shefi O, Baranes K (2019) A leech brain in the dish: a method for detailed analysis of specifically labeled single cells. Neural Imaging Sens 201:10865.

Croq F, Vizioli J, Tuzova M, Tahtouh M, Sautiere P-E, Van Camp C, Salzet M, Cruikshank WW, Pestel J, Lefebvre C (2010) A homologous form of human interleukin 16 is implicated in microglia recruitment following nervous system injury in leech Hirudo medicinalis. Glia 58:1649-1662.

Davalos D, Grutzendler J, Yang G, Kim JV, Zuo Y, Jung S, Littman DR, Dustin ML, Gan WB (2005) ATP mediates rapid microglial response to local brain injury in vivo. Nat Neurosci 8:752-758.

David S, Kroner A (2011) Repertoire of microglial and macrophage responses after spinal cord injury. Nat Rev Neurosci 12:388-399.

Dodd J, Jessell TM (1988) Axon guidance and the patterning of neuronal projections in vertebrates. Science 242:692-699.

Drago F, Sautière PE, Le Marrec-Croq F, Accorsi A, Van Camp C, Salzet M, Lefebvre C, Vizioli J (2014) Microglia of medicinal leech (Hirudo medicinalis) express a specific activation marker homologous to vertebrate ionized calcium-binding adapter molecule 1 (Iba1/alias aif-1). Dev Neurobiol 74:987-1001.

Duan X, Qiao M, Bei F, Kim IJ, He Z, Sanes JR (2015) Subtype-specific regeneration of retinal ganglion cells following axotomy: effects of osteopontin and mtor signaling. Neuron 85:1244-1256.

Duan Y, Haugabook SJ, Sahley CL, Muller KJ (2003) Methylene blue blocks cGMP production and disrupts directed migration of microglia to nerve lesions in the leech CNS. J Neurobiol 57:183-192.

Duan Y, Sahley CL, Muller KJ (2009) ATP and NO dually control migration of microglia to nerve lesions. Dev Neurobiol 69:60-72.

Elzinga K, Tyreman N, Ladak A, Savaryn B, Olson J, Gordon T (2015) Brief electrical stimulation improves nerve regeneration after delayed repair in Sprague Dawley rats. Exp Neurol 269:142-153.

English AW, Schwartz G, Meador W, Sabatier MJ, Mulligan A (2007) Electrical stimulation promotes peripheral axon regeneration by enhanced neuronal neurotrophin signaling. Dev Neurobiol 67:158172.

Fan RJ, Marin-Burgin A, French KA, Otto Friesen W (2005) A dye mixture (Neurobiotin and Alexa 488) reveals extensive dye-coupling among neurons in leeches; physiology confirms the connections. J Comp Physiol A Neuroethol Sens Neural Behav Physiol 191:1157-1171.

Ferguson TA, Son Y-J (2011) Extrinsic and intrinsic determinants of nerve regeneration. J Tissue Eng 2:2041731411418392.

Ferrari A, Cecchini M, Dhawan A, Micera S, Tonazzini I, Stabile R, Pisignano D, Beltram F (2011) Nanotopographic control of neuronal polarity. Nano Lett 11:505-511.

Ferreira LMR, Floriddia EM, Quadrato G, Di Giovanni S (2012) Neural regeneration: lessons from regenerating and non-regenerating systems. Mol Neurobiol 46:227-241.

Ferretti P, Zhang F, O'Neill P (2003) Changes in spinal cord regenerative ability through phylogenesis and development: lessons to be learnt. Dev Dyn 226:245-256.
Firme CP, Natan RG, Yazdani N, Macagno ER, Baker MW (2012) Ectopic expression of select innexins in individual central neurons couples them to pre-existing neuronal or glial networks that express the same innexin. J Neurosci 32:14265-14270.

Fixler D, Yitzhaki S, Axelrod A, Zinman T, Shainberg A (2012) Correlation of magnetic $\mathrm{AC}$ field on cardiac myocyte $\mathrm{Ca}(2+)$ transients at different magnetic DC levels. Bioelectromagnetics 33:634-640.

Gabel CV, Antoine F, Chuang CF, Samuel ADT, Chang C (2008) Distinct cellular and molecular mechanisms mediate initial axon development and adult-stage axon regeneration in C. elegans. Development 135:1129-1136.

Geddes LA, Hoff HE (1971) The discovery of bioelectricity and current electricity the Galvani-Volta controversy. IEEE Spectr 8:3846.

Geremia NM, Gordon T, Brushart TM, Al-Majed AA, Verge VMK (2007) Electrical stimulation promotes sensory neuron regeneration and growth-associated gene expression. Exp Neurol 205:347-359.

Giger RJ, Hollis ER, Tuszynski MH (2010) Guidance molecules in axon regeneration. Cold Spring Harb Perspect Biol 2:a001867.

Gordon T (2016) Electrical stimulation to enhance axon regeneration after peripheral nerve injuries in animal models and humans. Neurotherapeutics 13:295-310.

Gordon T, Udina E, Verge VMK, de Chaves EIP (2009) Brief electrical stimulation accelerates axon regeneration in the peripheral nervous system and promotes sensory axon regeneration in the central nervous system. Motor Control 13:412-441.

Hanisch UK, Kettenmann H (2007) Microglia: active sensor and versatile effector cells in the normal and pathologic brain. Nat Neurosci 10:1387-1394.

Hathway GJ, Vega-Avelaira D, Moss A, Ingram R, Fitzgerald M (2009) Brief, low frequency stimulation of rat peripheral C-fibres evokes prolonged microglial-induced central sensitization in adults but not in neonates. Pain 144:110-118.

Hoff HE (1936) Galvani and the pre-Galvanian electrophysiologists. Ann Sci 1:157-172.

Hoffman H (1952) Acceleration and retardation of the process of axon-sprouting in partially devervated muscles. Aust $\mathrm{J}$ Exp Biol Med Sci 30:541-566.

Hu G, Huang K, Hu Y, Du G, Xue Z, Zhu X, Fan G (2016) Single-cell RNA-seq reveals distinct injury responses in different types of DRG sensory neurons. Sci Rep 6:31851.

Huebner EA, Strittmatter SM (2009) Axon regeneration in the peripheral and central hervous systems. Results Probl Cell Differ 48:339351.

Jacobs AJ, Swain GP, Snedeker JA, Pijak DS, Gladstone LJ, Selzer ME (1997) Recovery of neurofilament expression selectively in regenerating reticulospinal neurons. J Neurosci 17:5206-5220.

Kandel ER (2012) The molecular biology of memory: CAMP, PKA, CRE, CREB-1, CREB-2, and CPEB. Mol Brain 5:14.

Kennedy TE, Wang H, Marshall W, Tessier-Lavigne M (2006) Axon guidance by diffusible chemoattractants: a gradient of netrin protein in the developing spinal cord. J Neurosci 26:8866-8874.

Kim YT, Haftel VK, Kumar S, Bellamkonda RV (2008) The role of aligned polymer fiber-based constructs in the bridging of long peripheral nerve gaps. Biomaterials 29:3117-3127.

Kreutzberg GW (1996) Microglia: a sensor for pathological events in the CNS. Trends Neurosci 19:312-318.

Kristan WB, Calabrese RL, Friesen WO (2005) Neuronal control of leech behavior. Prog Neurobiol 76:279-327.

Kuffler SW, Nicholls JG (1966) The physiology of neuroglial cells. Ergebnisse Physiol Biol Chemie Exp Pharmakologie 57:1-90.

Lee W, Frank CW, Park J (2014) Directed axonal outgrowth using a propagating gradient of IGF-1. Adv Mater Weinheim 26:49364940.

Li GN, Liu J, Hoffman-Kim D (2008) Multi-molecular gradients of permissive and inhibitory cues direct neurite outgrowth. Ann Biomed Eng 36:889-904. 
Lurie DI, Selzer ME (1991) Preferential regeneration of spinal axons through the scar in hemisected lamprey spinal cord. J Comp Neurol 313:669-679.

Macagno ER (1980) Number and distribution of neurons in leech segmental ganglia. J Comp Neurol 190:283-302.

Macagno ER, Muller KJ, DeRiemer SA (1985) Regeneration of axons and synaptic connections neurons in the leech central nervous system by touch sensory. J Neurosci 5:2510-2521.

MacEwan MR, Gamble P, Stephen M, Ray WZ (2019) Therapeutic electrical stimulation of injured peripheral nerve tissue using implantable thin-film wireless nerve stimulators. J. Neurosurg 130:486-495.

Mackler SA, Yin HS, Selzer ME (1986) Determinants of directional specificity in the regeneration of lamprey spinal axons. J Neurosci 6:1814-1821.

Marcus M, Baranes K, Park M, Choi IS, Kang K, Shefi O (2017) Interactions of neurons with physical environments. Adv Healthcare Mater 6:1700267.

Le Marrec-Croq F, Drago F, Vizioli J, Sautière P-E, Lefebvre C (2013) The leech nervous system: a valuable model to study the microglia involvement in regenerative processes. Clin Dev Immunol 2013:274019.

McCaig CD, Rajnicek AM, Song B, Zhao M (2005) Controlling cell behavior electrically: current views and future potential. Physiol Rev 85:943-978.

McCaig CD, Song B, Rajnicek AM (2009) Electrical dimensions in cell science. J Cell Sci 122:4267-4276.

McGlade-McCulloh E, Morrissey a. M, Norona F, Muller KJ (1989) Individual microglia move rapidly and directly to nerve lesions in the leech central nervous system. Proc Natl Acad Sci USA 86:1093-1097.

McLean NA, Verge VMK (2016) Dynamic impact of brief electrical nerve stimulation on the neural immune axis-polarization of macrophages toward a pro-repair phenotype in demyelinated peripheral nerve. Glia 64:1546-1561.

Meijering E, Jacob M, Sarria J-CF, Steiner $P$, Hirling $H$, Unser $M$ (2004) Design and validation of a tool for neurite tracing and analysis in fluorescence microscopy images. Cytometry A 58:167-176.

Messerli MA, Graham DM (2011) Extracellular electrical fields direct wound healing and regeneration. Biol Bull 221:79-92.

Miller C, Jeftinija S, Mallapragada S (2002) Synergistic effects of physical and chemical guidance cues on neurite alignment and outgrowth on biodegradable polymer substrates. Tissue Eng 8:367-378.

Ming GL, Henley J, Tessier-Lavigne M, Song HJ, Poo MM (2001) Electrical activity modulates growth cone guidance by diffusible factors. Neuron 29:441-452.

Mladinic M, Muller KJ, Nicholls JG (2009) Central nervous system regeneration: from leech to opossum. J Physiol 587:2775-2782.

Morgese VJ, Elliott EJ, Muller KJ (1983) Microglial movement to sites of nerve lesion in the leech CNS. Brain Res 272:166-170.

Ngu EM, Sahley CL, Muller KJ (2007) Reduced axon sprouting after treatment that diminishes microglia accumulation at lesions in the leech CNS. J Comp Neurol 503:101-109.

Nicholls JG, Baylor DA (1968) Specific modalities and receptive fields of sensory neurons in CNS of the leech. Specific modalities and receptive fields of sensory neurons in CNS of the leech. J Neurophysiol 31:740-756.

Nix WA, Hopf HC (1983) Electrical stimulation of regenerating nerve and its effect on motor recovery. Brain Res 272:21-25.

Ou YT, Lu MS, Chiao CC (2012) The effects of electrical stimulation on neurite outgrowth of goldfish retinal explants. Brain Res 1480:22-29.

Palgi M, Lindström R, Peränen J, Piepponen TP, Saarma M, Heino TI (2009) Evidence that DmMANF is an invertebrate neurotrophic factor supporting dopaminergic neurons. Proc Natl Acad Sci USA 106:2429-2434.

Patel N, Poo MM (1982) Orientation of neurite growth by extracellular electric fields. J Neurosci 2:483-496.
Piccolino M (1997) Luigi Galvani and animal electricity: two centuries after the foundation of electrophysiology. Trends Neurosci 20:443-448.

Pirschel F, Kretzberg J (2016) Multiplexed population coding of stimulus properties by leech mechanosensory cells. J Neurosci 36:3636-3647.

Pockett S, Gavin RM (1985) Acceleration of peripheral nerve regeneration after crush injury in rat. Exp Neurol 59:221-224.

Podda MV, Leone L, Barbati SA, Mastrodonato A, Li Puma DD, Piacentini R, Grassi C (2014) Extremely low-frequency electromagnetic fields enhance the survival of newborn neurons in the mouse hippocampus. Eur J Neurosci 39:893-903.

Puhl JG, Bigelow AW, Rue MCP, Mesce KA (2018) Functional recovery of a locomotor network after injury: plasticity beyond the central nervous system. eNeuro 5:ENEURO.0195-18.2018.

Ready DF, Nicholls J (1979) Identified neurones isolated from leech CNS make selective connections in culture. Nature 281:67-69.

Rodríguez FJ, Verdú E, Ceballos D, Navarro X (2000) Nerve guides seeded with autologous Schwann cells improve nerve regeneration. Exp Neurol 161:571-584.

Rosoff WJ, Urbach JS, Esrick MA, McAllister RG, Richards LJ, Goodhill GJ (2004) A new chemotaxis assay shows the extreme sensitivity of axons to molecular gradients. Nat Neurosci 7:678682.

Salzet M, Macagno E (2009) Recent advances on development, regeneration and immune responses of the leech nervous system. In: Annelids as Models Systems in the Biological Sciences, pp. 156-184. Hoboken: Wiley Blackwell.

Samuels SE, Lipitz JB, Dahl G, Muller KJ (2010) Neuroglial ATP release through innexin channels controls microglial cell movement to a nerve injury. J Gen Physiol 136:425-442.

Schikorski D, Cuvillier-Hot V, Leippe M, Boidin-Wichlacz C, Slomianny C, Macagno E, Salzet M, Tasiemski A (2008) Microbial challenge promotes the regenerative process of the injured central nervous system of the medicinal leech by inducing the synthesis of antimicrobial peptides in neurons and microglia. J Immunol 181:1083-1095.

Schwartz M (2003) Macrophages and microglia in central nervous system injury: are they helpful or harmful? J Cereb Blood Flow Metab 23:385-394.

Shefi O, Simonnet C, Baker MW, Glass JR, Macagno ER, Groisman A (2006) Microtargeted gene silencing and ectopic expression in live embryos using biolistic delivery with a pneumatic capillary gun. J Neurosci 26:6119-6123.

Shifman MI, Selzer ME (2007) Differential expression of class 3 and 4 semaphorins and netrin in the lamprey spinal cord during regeneration. J Comp Neurol 501:631-646.

Sieger D, Peri F (2013) Animal models for studying microglia: the first, the popular, and the new. Glia 61:3-9.

Siemionow M, Brzezicki G (2009) Current techniques and concepts in peripheral nerve repair. Int Rev Neurobiol 87:141-172.

Singh B, Xu Q-G, Franz CK, Zhang R, Dalton C, Gordon T, Verge VMK, Midha R, Zochodne DW (2012) Accelerated axon outgrowth, guidance, and target reinnervation across nerve transection gaps following a brief electrical stimulation paradigm. J Neurosurg 116:498-512.

Song B, Zhao M, Forrester J, McCaig C (2004) Nerve regeneration and wound healing are stimulated and directed by an endogenous electrical field in vivo. J Cell Sci 117:4681-4690.

Tahtouh M, Garçon-bocquet A, Croq F, Vizioli J, Sautière P, Camp C, Van Salzet M, Meillour PN, Pestel J, Lefebvre C (2012) Interaction of $\mathrm{Hm} \mathrm{C1q}$ with leech microglial cells: involvement of C1qBP-related molecule in the induction of cell chemotaxis. J Neuroinflammation 9:37.

Tasset I, Medina FJ, Jimena I, Agüera E, Gascón F, Feijóo M, SánchezLópez F, Luque E, Peña J, Drucker-Colín R, Túnez I (2012) Neuroprotective effects of extremely low-frequency electromagnetic fields on a Huntington's disease rat model: effects on neurotrophic factors and neuronal density. Neuroscience 209:54-63. 
Titlow J, Majeed ZR, Nicholls JG, Cooper RL (2013) Intracellular recording, sensory field mapping, and culturing identified neurons in the leech, Hirudo medicinalis. J Vis Exp (81):e50631.

Tomina Y, Wagenaar DA (2017) A double-sided microscope to realize whole-ganglion imaging of membrane potential in the medicinal leech. Elife 6:e29839.

von Bernhardi R, Muller KJ (1995) Repair of the central nervous system: lessons from lesions in leeches. J Neurobiol 27:353-366.

von Philipsborn AC, Lang S, Loeschinger J, Bernard A, David C, Lehnert D, Bonhoeffer F, Bastmeyer M (2006) Growth cone navigation in substrate-bound ephrin gradients. Development 133:2487-2495.

Wang WZ, Emes RD, Christoffers K, Verrall J, Blackshaw SE (2005) Hirudo medicinalis: a platform for investigating genes in neural repair. Cell Mol Neurobiol 25:427-440.

Wong JN, Olson JL, Morhart MJ, Chan KM (2015) Electrical stimulation enhances sensory recovery: a randomized controlled trial. Ann Neurol 77:996-1006.
Wood M, Willits RK (2006) Short-duration, DC electrical stimulation increases chick embryo DRG neurite outgrowth. Bioelectromagnetics 27:328-331.

Wu Z, Ghosh-Roy A, Yanik MF, Zhang JZ, Jin Y, Chisholm AD (2007) Caenorhabditis elegans neuronal regeneration is influenced by life stage, ephrin signaling, and synaptic branching. Proc Natl Acad Sci USA 104:15132-15137.

Yan D, Wu Z, Chisholm AD, Jin Y (2009) The DLK-1 kinase promotes mRNA stability and local translation in $C$. elegans synapses and axon regeneration. Cell 138:1005-1018.

Yanik MF, Cinar H, Cinar HN, Chisholm AD, Jin Y, Ben-Yakar A (2004) Functional regeneration after laser axotomy. Nature 432:822.

Zareen N, Shinozaki M, Ryan D, Alexander H, Am A, Truong DQ, Khadka N, Sarkar A, Naeem S, Bikson M, Martin JH (2017) Motor cortex and spinal cord neuromodulation promote corticospinal tract axonal outgrowth and motor recovery after cervical contusion spinal cord injury. Exp Neurol 297:179-189. 